\title{
Modeling the innovative development of the economy based on the investment demand prognosis
}

\author{
Rufina Ivanova ${ }^{1}$ [0000-0002-2964-2301], Dilyara Mukhametzyanova, Olga Belay1 [0000-0002-2994-2830], \\ Rustem Sirazetdinov ${ }^{10000-0001-9714-071 x]}$, and Ella Biktemirova ${ }^{1}{ }^{\text {[0000-0002-4165-3134] }}$ \\ ${ }^{1}$ Kazan State University of Architecture and Engineering, 420043, Zelenaya st., Kazan, Russia
}

\begin{abstract}
The effectiveness of innovation activity is largely determined by the relevant infrastructure which is the basic component of a developed economy. The correlation between the development of the innovative economy and the intensification of investment activity is revealed.

On the basis of retrospective analysis of trends and patterns in the development of investment activity, an assessment of the resource support of the investment process in the Republic of Tatarstan is carried out. The need for advanced development of the production potential of the investment and construction complex of the region and the material and technical base on the basis of the development of the local raw material base is justified. An economic and mathematical model of the interaction of investment recourses that determine the level of innovative development of the region is proposed. On the basis of the theory of factor models, the quantitative relationships between the factors that have the greatest impact on investment development are investigated. They are: gross regional product, investment in fixed assets, the volume of contract work, the volume of investment in housing construction, the cost of research and development in the gross regional product, the share of innovation costs in industrial investment.
\end{abstract}

Keywords: innovation potential, investment of innovation, resource provision of the investment process, investment demand.

\section{Introduction}

Based on the experience of many countries and objective economic patterns, the growth of the level of innovative development is associated with an indispensable increase in investment activity, an increase in the volume of capital investments in new construction and reconstruction of fixed assets with the advanced development of the production potential of the construction industry and its material and technical base [1]. A necessary condition for this is to increase the efficiency of capital construction, including the rational use of investment resources, directing them to programs and projects that give the greatest

\footnotetext{
* Corresponding author: bikti77@yahoo.com
} 
economic and social effect, as well as increasing the operational profitability of investment projects $[2,3]$.

The investment and construction complex as an integral economic system exists only at the regional level, and this position is justified in a number of serious scientific studies [4, 5]. The national (federal) market of construction products, as well as the market of products of the construction materials and construction industry, can be represented as a set of local, regional markets. At the same time, each regional market is characterized by a certain uniqueness of its formation, functioning and development processes [6-8].

The Republic of Tatarstan is one of the most competitive and investment-attractive regions of the Russian Federation. This is confirmed by the data of international rating agencies [9].

More active attraction of borrowed funds in recent years has allowed enterprises to deal with the problems of renovation and modernization of their worn-out fixed assets at an accelerated pace $[10,11]$.

The main reason for the unsatisfactory condition of fixed assets in construction, the lack of replenishment of the fleet of machines and mechanisms with new construction equipment is the lack of own financial resources for the implementation of investment projects $[12,13]$.

The unsatisfactory state of the domestic construction industry and the building materials industry, along with other reasons, is largely due to the systematically insufficient resource support for scientific research and experimental industrial developments. With the total contribution of the construction industry and the construction materials industry to the GDP of the Russian Federation of about $10 \%, \mathrm{R} \& \mathrm{D}$ costs are less than 1\%. In many regions, this indicator is much lower, while in technically developed countries, this indicator is 6$8 \%$. In this regard, the research, development and experimental base of the domestic investment and construction sector is also insufficiently developed [14-16].

The cost of raw materials and energy resources per unit of production in the construction industry as a whole in Russia is $2-3$ times higher than in other technically developed countries [17].

Programme methods and State support are needed to address the problem of increased reproduction of fixed capital and further sustainable development of the construction complex $[18,19]$.

This need is dictated by the following motives:

- in recent years, the reduction of the fleet of construction mechanisms on the balance sheet of organizations has stopped, which is a positive trend.

- high wear and tear of the equipment, and its nomenclature does not always correspond to the new technologies introduced in the industry in recent years;

- the share of manual labor in construction is still high;

- the material consumption of construction products is constantly increasing: the share of construction materials in the cost price is $64.6 \%$;

- low level of use of small-scale mechanization: in the structure of the main funds of construction organizations. One of the strategic goals of the state is the implementation of the national priority project in the field of creating a market for affordable and comfortable housing that meets the housing needs of the majority of the population [20].

Investments in the housing sector have some specific features, such as long-term investments and long capital turnover, low liquidity, the need for a significant amount of initial capital to enter the market, relatively high reliability and efficiency of investments, provided by the object of investment itself [21].

The negative trends caused by the situation in the banking sector of the economy, combined with the increasing risks of nonfulfillment of built housing, have created serious difficulties for professional participants in the entire chain of investment and construction 
activities, to which small and medium-sized companies with a smaller margin of safety are particularly sensitive [22].

The formation of an affordable housing market will be possible only if there is a balanced stimulation of the effective demand of the population for housing and the supply in the housing market. An increase in demand for housing without an adequate acceleration in the pace of housing construction will lead to a rapid increase in prices in the housing market. At the same time, the development of housing construction is impossible without the availability of effective demand, corresponding to the supply of housing [23].

The conducted research allowed us to conclude that it is impossible to try to instantly restore investment activity. No economy is ready for this during the crisis, as its most important parameters are not clear: the ratio of economic interests of business entities, demand parameters, the price of money and development resources, the profitability of projects, the trajectory of national currency exchange rates, and a number of other parameters. Before returning to the strategic trend of development, it is necessary not only to identify a new point of equilibrium, but also to provide the participants of the new growth trajectory with legislative and managerial tools. In addition, as we approach the tipping point of the inter-phase transition, all the positive effects of the crisis should be materialized: a sharp reduction in production costs, structural shifts in the economy, stabilization of prices in the real estate market, rental rates and non-productive services, resource mobilization within the framework of public-private partnerships, etc. [24].The purpose of the study is to develop economic and mathematical models of the relationship of investment resources that determine the level of innovative development of the region. On the basis of the theory of factor models, the quantitative relationships between the factors that have the greatest impact on investment development are investigated.

\section{Methods}

The trend line method is used to check the prognosis.

To identify the relationship of indicators in our work we use graphical and analytical method of regression analysis. One of the regression analysis tools that we will use is plotting a trend line. The advantages of this regression analysis tool are:

Relative ease of plotting a trend line without creating a data table for it;

A fairly wide list of types of proposed trend lines, and this list includes the most commonly used types of regression;

The possibility to obtain the equation of the trend line in an analytical form;

The possibility, if necessary, to obtain an assessment of the reliability of the approximation.

It is possible to build the following types of regressions:

1. Linear regression is good for modeling characteristics the values of which increase or decrease with constant speed. This is the simplest model for the process under the study. It is built according to the equation:

$$
y=m x+b
$$

where $m$-is linear regression slope tangent to the abscissa axis;

$b$-is linear regression intersection coordinates with the ordinate axis.

2. The polynomial trend line is useful for describing characteristics that have several pronounced extrema (highs and lows). In this case, the trend line is plotted in accordance with the equation:

$$
y=c 0+c 1 x+c 2 x 2+c 3 \times 3+c 4 x 4+c 5 \times 5+c 6 x 6,
$$


where the coefficients $c 0, c 1, c 2, . . c 6$ - are constants, their values are determined during construction.

3. The logarithmic trend line is successfully used in modeling characteristics, the values of which change rapidly at first, and then gradually stabilize. It is built in accordance with the equation:

$$
y=c \ln (x)+b,
$$

where the coefficients $b, c$ - constants.

4. Power trend line gives good results if the values of the studied dependence are characterized by a constant change in the growth rate. It is built in accordance with the equation:

$$
y=c x b
$$

where the coefficients $b$ and $c$ are constants.

5. An exponential trend line should be used when the rate of change of data is continuously increasing. For data containing zero or negative values, this kind of approximation is also inapplicable. It is built in accordance with the equation:

$$
y=c e b x
$$

where the coefficients $b, c-$ constants.

\section{Results and discussion}

The period of 2011-2020 is characterized by conditions favorable for accelerated economic growth. There are several reasons for this assumption. Firstly, by this time, the industries and corporations possessing sufficient competitiveness had already been clearly defined, ineffective enterprises in traditional sectors of the economy had disappeared or were repurposed. Secondly, effective science-intensive and high-tech industries had been formed - the basis of post-industrial development. Thirdly, as a result of the restructuring of the economy, the implementation of programs to attract to the republic, one can expect a largescale inflow of investments and the latest technologies. Fourth, the scientific and human potential will actively work on the development of the «new economy» and the transformation of the service sector. After accelerated growth in the period of 2011-2020, it is assumed that the main factors determining growth in Tatarstan will be high-tech innovative industries capable of ensuring high rates of production growth in the Republic. Such a significant increase in volume of the planned activities will be facilitated by a significant increase in investments in fixed assets of the Republic of Tatarstan. Their growth is also significantly ahead of the emerging tendency of today. The forecast of changes in the volume of investments in fixed assets of the Republic of Tatarstan is clearly shown in

\begin{tabular}{|c|c|c|c|c|c|c|c|c|c|c|c|c|c|}
\hline & ஓ̊̊ & 홍 & 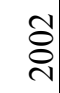 & శ̊ & ষ্ণ & ?̊ & ஓ̊ & 용 & $\begin{array}{l}\stackrel{0}{\sigma} \\
\stackrel{2}{N}\end{array}$ & 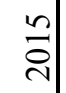 & $\begin{array}{l}\text { సి } \\
\text { సે }\end{array}$ & તి & లి \\
\hline $\begin{array}{c}\text { Fixed } \\
\text { asset } \\
\text { formation }\end{array}$ & $\begin{array}{l}\forall \\
\ddot{\circ}\end{array}$ & $\begin{array}{l}0 \\
\text { తి}\end{array}$ & $\vec{\bullet}$ & $\stackrel{?}{\circ}$ & $\begin{array}{l}0 \\
\dot{a}\end{array}$ & $\begin{array}{l}\text { मे. } \\
\text { ભे }\end{array}$ & $\begin{array}{l}a \\
\infty \\
\stackrel{n}{n}\end{array}$ & $\stackrel{\infty}{\varrho}$ & $\begin{array}{l}\dot{+} \\
\stackrel{\infty}{+}\end{array}$ & $\begin{array}{l}\vec{m} \\
\infty \\
\dot{n}\end{array}$ & $\begin{array}{l}\stackrel{+}{ \pm} \\
\Phi \\
\Xi\end{array}$ & $\begin{array}{l}\stackrel{+}{*} \\
\stackrel{f}{n}\end{array}$ & $\frac{n}{0}$ \\
\hline
\end{tabular}
Table 1.

Table 1. Forecast of investments in fixed assets, billion rubles fixed capital investment. 
Let us analyze the influence of the volume of investments in fixed assets on the implementation of the measures planned in the Republic. To do this, we select the regression equation by constructing a trend line.

$\mathrm{y}=0.5571 \mathrm{x}+26.827, \mathrm{R}^{2}=0.9947$ - Linear regression equation for indicators of the volume of contract work and investment in fixed assets of the Republic of Tatarstan;

$\mathrm{y}=0 / 4599 \mathrm{x}^{1,04}, \mathrm{R}^{2}=0,9773$ - Power regression equation for indicators of the volume of contract work and investment in the fixed assets of the Republic of Tatarstan;

$\mathrm{y}=286.16 \operatorname{Ln}(\mathrm{x})-1301.9, \mathrm{R}^{2}=0.8844-$ Logarithmic regression equation for indicators of the volume of contract work and investment in fixed assets of the Republic of Tatarstan;

$y=75.354 \mathrm{e}^{0,0017 x}, \mathrm{R}^{2}=0.7627$ - Exponential regression equation for indicators of the volume of contract work and investment in fixed assets of the Republic of Tatarstan;

$y=-9 E-0.5 \times 2+0.7121 x-9.8299, R^{2}=0.7627$ - Polynomial regression equation for indicators of the volume of contract work and investment in fixed assets of the Republic of Tatarstan.

The most reliable are the models with linear and polynomial trends, since their accuracy is the highest. But calculations using a polynomial model are much more complicated than those using a linear one. Therefore, the forecast made on the basis of the linear model data will be the most preferable.

A deeper analysis of the linear model showed that $\mathrm{R}^{2}=0.9947$, which means that the share of the explained variance of the trait of the dependent variable $\mathrm{Y}$ in the total variance is $99.47 \%$, and $0.53 \%$ falls on the share of unaccounted factors. Since $r=0.997$, the connection is direct and strong.

The significance of the regression coefficients is determined using the Student's F-test. Since $\mathrm{T} o b s \mathrm{~b}>\mathrm{T} c r \mathrm{~b}$, then the regression coefficient is significant for $\mathrm{b}$, and $\mathrm{T} o b s \mathrm{a}>\mathrm{T} c r \mathrm{a}$, then the regression coefficient is significant for $a$.

The significance of the regression equation as a whole is assessed using Fisher's F-test:

$$
F=\frac{R^{2}}{1-R} \cdot \frac{n m}{m}
$$

Fobs. $>$ Fcr, which means that the regression equation is significant.

It can be concluded that with a decrease in the volume of investments by 1 billion rubles, the volume of work performed decreases on average by 557 million rubles. The coefficient of elasticity $\mathrm{E}=0.943$, which means that with a decrease in the volume of investments by $1 \%$, the volume of planned work will, on average, decrease by $0.94 \%$.

The dependencies considered above served as a basis for the development and testing of economic and statistical models for forecasting investment demand, allowing determining the need for investments in the framework of medium and long term forecasting.

Investment activity, first of all, depends on the investment demand associated, firstly, with the replacement and renewal of technological equipment. The demand for investments in fixed assets is a derived demand due to the presence of demand for the products or services of the invested object, the need to increase its production capacity.

Investment forecasting is a multistage process of studying the directions of probabilistic capital investment in a particular area of the economy in the future. It is carried out at the macro-, meso- and microeconomic levels of the national economy and involves:

- analysis of trends in the field of investment activities;

- variant foresight of the future development of various sectors of the economy as objects of capital investment;

- choice of forecasting methods;

- assessment of the possibilities and consequences of investing in a particular sector of the economy

Short-term, medium-and long-term prognoses are usually developed. The long-term prognosis is primarily due to the development of an investment strategy and the investment of funds in large capital-intensive investment objects. Short-and medium-term prognosis are 
used to develop tactics and adjust the strategy of investment activity. Depending on the tasks set, different prognostic methods are used. The projected volumes of investment flows can be determined by the following main methods:

- by the share of investments in GNP;

- according to the increase in production capacity;

- based on the capital investment structure;

- based on a multi-factor model;

- using an input-output balance.

\subsection{Short-term prediction of investment activity}

In the framework of short-term forecasting of investment activity of the Republic of Tatarstan, the authors used a method for determining the volume of investments based on the structure of capital investments (at the industry level). According to the forecast model, the calculation of the industry's capital investment needs in the forecast year includes three components: the need for investments to recover the retiring fixed capital $I \downarrow(t, 1) \uparrow A)$ the need for investments to increase fixed capital $\Delta \mathrm{M} \downarrow(t+1)$ and the need for investments due to construction in progress.

The total investment demand of the industry is determined by the formula:

$$
I \downarrow(t+1) \uparrow)=I_{t+1}^{A}+\Delta I_{t+1}+\left(I_{t+1}^{Z}\right)
$$

The need for investments to recover the retiring fixed capital is determined by the formula:

$$
I_{t+1}^{A}=K_{t+1}^{A} \cdot K_{t}
$$

where $\mathrm{K}_{\mathrm{t}+1}^{\mathrm{A}}$ - is the coefficient of retirement reparation of the fixed capital of the industry in the predicted year.

The need for investment in fixed capital gains can be determined by the formula:

$$
\Delta I_{t+1}=K_{t+1}^{e}-K_{t}
$$

where $\mathrm{K}_{\mathrm{t}+1}^{\mathrm{e}}-$ is the capital intensity ratio of the industry in the predicted year $(\mathrm{t}+1)$;

$\mathrm{K}_{\mathrm{t}}$-the volume of the fixed capital of the industry in the base year.

When making calculations, it is necessary to take into account the need for investment due to construction in progress in the industry in the predicted year.

We will conduct a study of the dependence of the investment activity results on the size of the investment resources used. Let us evaluate the main statistical characteristics of the dynamic series under consideration (Table 2). Using the theory of cycles, the names of individual cyclical phases can be described as follows: the period 1992-1994 as a period of catastrophic collapse of production, the period 1995-1999, due to the slowdown in the rate of decline, is more correctly called a depression; and after 1999, the stage of economic growth came.

The recovery period is heterogeneous itself until 2005 and is unstable - high growth rates alternate with low ones, periods of stagnation are noticeable, and since 2009 - there has been the period of the financial crisis. Since 2015, there has been a trend of economic growth. To ease model building, we will give a brief description of the initial indicators (Table 3): 
Table 2. Dynamics of the main indicators of the construction industry development.

\begin{tabular}{|c|c|c|c|c|c|c|c|c|c|}
\hline \multicolumn{5}{|c|}{ Growth rate relative to $1992, \%$} & \multicolumn{3}{c|}{ Growth rate relative to the previous period, $\%$} \\
\hline Year & \multicolumn{3}{|c|}{ Indicators } & Year & \multicolumn{4}{c|}{ Indicators } \\
\hline & $V$ & $K_{I}$ & $K_{2}$ & $L$ & & $V$ & $K_{I}$ & $K 2$ & $L$ \\
\hline 1992 & 100 & 100 & 100 & 100 & 1992 & 100 & 100 & 100 & 100 \\
\hline 1993 & 102 & 93 & 98 & 97 & 1993 & 102 & 93 & 98 & 97 \\
\hline 1994 & 59 & 97 & 100.2 & 85 & 1994 & 58 & 104 & 101 & 88 \\
\hline 1995 & 77 & 101 & 101 & 82 & 1995 & 130 & 104 & 101 & 96 \\
\hline 1996 & 71 & 97 & 105 & 75 & 1996 & 92 & 96 & 103 & 91 \\
\hline 1997 & 68 & 70 & 87 & 68 & 1997 & 96 & 72 & 83 & 90 \\
\hline 1998 & 69 & 72 & 96 & 52 & 1998 & 101 & 102 & 109 & 76 \\
\hline 1999 & 68 & 67 & 101 & 47 & 1999 & 98 & 93 & 105 & 92 \\
\hline 2000 & 80 & 62 & 106 & 49 & 2000 & 117 & 92 & 104 & 102 \\
\hline 2001 & 88 & 65 & 106 & 48 & 2001 & 108 & 105 & 100.2 & 98 \\
\hline 2002 & 85 & 80 & 101 & 47 & 2002 & 97 & 122 & 95 & 98 \\
\hline 2003 & 87 & 86 & 103 & 47 & 2003 & 102 & 107 & 101 & 98 \\
\hline 2004 & 90 & 82 & 102 & 46 & 2004 & 103 & 95 & 99 & 98 \\
\hline 2005 & 95 & 83 & 104 & 45 & 2005 & 105 & 100.8 & 101 & 98 \\
\hline 2010 & 138 & 76 & 101 & 55 & 2010 & 145 & 92 & 97 & 121 \\
\hline 2015 & 228 & 73 & 101 & 88 & 2015 & 165 & 95 & 100 & 160 \\
\hline 2020 & 338 & 68 & 100 & 133 & 2020 & 148 & 93 & 98 & 150 \\
\hline 2025 & 475 & 61 & 99 & 195 & 2025 & 140 & 90 & 98 & 146 \\
\hline 2030 & 646 & 53 & 98 & 248 & 2030 & 136 & 86 & 98 & 127 \\
\hline
\end{tabular}

Table 3. Baseline indicators.

\begin{tabular}{|c|l|}
\hline$V$ & The volume of contract works \\
\hline$K 1$ & The share of investments in fixed capital for construction and installation works \\
\hline$K 2$ & $\begin{array}{l}\text { The share of investments in fixed capital for construction and installation works, equipment } \\
\text { and vehicles }\end{array}$ \\
\hline$L$ & The number of employees of construction organizations \\
\hline
\end{tabular}

Power-law calculations $\left(V=a *\left(K_{l}\left(K_{2}\right) b\right) *(L * c) \quad\right.$ and exponential $\left(V=\exp \left(a+\left(K_{1} * b\right)+\left(L^{*} c\right)\right)\right)$ models were carried out in the software product «STATISTICA» ( $a, b, c$ are the parameters of the model to be evaluated, we find them from the condition of minimizing the mean square deviation).

Considering a power model for predicting the volume of contract work for an innovative development option relative to the base growth rate (the base year is taken as 2002), we use the software product «STATISTICA 6». This model explains: $94.306837 \%$ of the variance of the variable $\mathrm{V}$ (volume of contract work). The multiple correlation coefficient in this case is $\mathrm{R}=0,971$. In this software product, the p-level is calculated (Table 4). Here is an explanation of this expression.

Table 4. Calculated significance of constants $a, b, c$.

\begin{tabular}{|c|c|c|c|c|c|c|}
\hline & \multicolumn{2}{|c|}{ Indicator estimation } & \multicolumn{2}{c|}{ Standard error } & \multicolumn{2}{c|}{$\mathrm{p}$} \\
\hline & $\mathrm{V}_{1}$ & $\mathrm{~V}_{2}$ & $\mathrm{~V}_{1}$ & $\mathrm{~V}_{2}$ & $\mathrm{~V}_{1}$ & $\mathrm{~V}_{2}$ \\
\hline $\mathrm{A}$ & 1.228 & 1.697 & 0.193 & 0.163 & 0.0001 & 0.0001 \\
\hline $\mathrm{B}$ & -1.243 & 4.638 & 0.415 & 4.313 & 0.009 & 0.298 \\
\hline $\mathrm{C}$ & 1.014 & 1.569 & 0.143 & 0.174 & 0.0001 & 0.0001 \\
\hline
\end{tabular}


where,

$$
\begin{aligned}
& \mathrm{V}_{1}=\left(\mathrm{V}=\alpha \cdot\left(\mathrm{K}_{1} \mathrm{~b}\right)(\mathrm{Lc})\right. \\
& \mathrm{V}_{2}=\left(\mathrm{V}=\alpha^{\kappa}\left(K_{2} \mathrm{~b}\right)(\mathrm{Lc}) .\right.
\end{aligned}
$$

The statistical significance of the result is an estimated measure of confidence in its correctness. The significance level shows how significant the result is for us. Formally speaking, the level of significance, or, as they say, the p-level, is an indicator that is in decreasing dependence on the reliability of the result. A higher p-level corresponds to a lower level of confidence in the relationship between the variables found in the sample. It is the $p$ level that represents the probability of error associated with the distribution of the observed result to the entire population. For example, the p-level $=0.05$ (i.e. 1/20) indicates that there is a $5 \%$ probability that the relationship between the variables found in the sample is only a random feature of this sample. In many studies, a p-level of 0.05 is considered an «acceptable limit» of the error level. Analyzing Table 4, we see that the three constants under consideration are of great importance for determining the volume of contract work.

Consider a power-law model, where K2 is considered as the share in the main capital of construction and installation works, equipment and vehicles, we get the following result: the model explains: $91.247 \%$ (coefficient of determination) of the variance of the variable $\mathrm{V}$. Multiple correlation coefficient $\mathrm{R}=0.95523$.

Table 4 shows that the coefficient before the constant $b$, the specific weight in the main capital of construction and installation works, equipment and vehicles (K2) is not significant for the constructed power model. The developed models allow us to determine the dependence of the rate of investment activity on the size of the investment resources used and can serve as a basis for determining the form of economic development.

\section{Conclusions}

The conducted research allowed us to conclude that it is impossible to instantly restore investment activity. No economy is ready for this during the crisis, as its most important parameters are not clear: the ratio of economic interests of business entities, demand parameters, the price of money and development resources, the profitability of projects, the trajectory of national currencies, etc. Before returning to the strategic trend of development, it is necessary not only to identify a new point of equilibrium, but also to provide the participants of the new growth trajectory with legislative and managerial tools. In addition, as we approach the turning point of the inter-phase transition, all the positive effects of the crisis should be materialized: a sharp reduction in production costs, structural shifts in the economy, stabilization of prices in the real estate market, rental rates and non-productive services, resource mobilization within the framework of public-private partnerships, etc.

In general, the stability of the investment and construction sector depends on the speed of recovery from the crisis and the level of losses as a result of its overcoming.

\section{References}

1. A. N. Asaul, M. P. Voynarenko, L. V. Skorobogata.Transformation of business capitalization model within the knowledge economy, Actual Problems of Economics, 161(11), 8-15 (2014)

2. A. I. Shinkevich, A. A. Lubnina, N. M. Chikisheva, R. S. Sadykova, R. R. Kharisova, Innovative forms of production organization in the context of high-tech meso-economic systems sustainable development, International Review of Management and Marketing, 6(2), 219-224 (2016) 
3. A. I. Romanova, D. S. Romanov, O. V. Maksimchuk, A. V. Voronin, Basic principles of innovation management in the urban economy of Smart-city, International Journal of Engineering and Technology (UAE), 7(4), 412-415 (2018)

4. N. V. Chepachenko, A. A. Leontiev, G. A. Uraev, V. D. Ardzinov, Modeling the effect of using the innovative materials on the construction organizations economic performance, IOP Conference Series: Materials Science and Engineering, 698(7), 077038 (2019)

5. J. M. C. Rodas, J. M. N. Gomez, R. A. Castanho, J. Cabezas, Land valuation sutainable model of urban planning development: A case study in Badajoz, Spain, Sutain. (2018) DOI: $16.3390 /$ sul0051450

6. .J. Zawistowski, J. Kulejewski, Influence of the contractor's payment method on the economic effectiveness of the construction project from the contractor's point of view, Open Eng., 8, 562-570 (2018) DOI10.1515/eng-2018-0055

7. D. Salem, A. Bakr, Z. El Sayad, Post-construction stages cost management: Sutainable design approach, Alexandria Eng. J., 57, 3429-3435 (2018) DOI: 10.1016/j.aej.2018.07.014

8. G. Zagidullina, R. Ivanova, G. Nugumanova, R. Sirazetdinov, A. Zaripova, The improvement of construction industry innovative potential through the creation of a cluster, IOP Conference Series: Materials Science and Engineering, 890(1), 012121 (2020) DOI:10.1088/1757-899X/890/1/012121

9. G. M. Zagidullina, A. R. Mavlyutova, Environmental standartization of residential real estate according to "Green standards», International Scientific Conference Environmental Science for Construction Industry, ESCI, EDP Sciences, 193, 16 (2018)

10. A. I. Romanova, G. M. Zagidullina, R. M. Ivanova, O. A. Kleshcheva, R. M. Sirazetdinov, Peculiarities of Housing Construction Development in the Region, Middle-East Journal of Scientific Research,16 (4), 490-495, (2013)

11. A. N. Afanasyeva, G. M. Zagidullina, A. I. Romanova, Experience in the Region to Increase the Availability of Housing Services, Mediterranean Journal of Social Sciences, 6(4), 549-554 (2015)

12. I. E. Fayzullin, Innovative development of urban planning policy, Electronic economic newsletter of the Republic of Tatarstan, 1, 249-263 (2012)

13. I. R. Nizamova, The position of the world economy and the Russian economy in the system of technological modes, Economic Systems Management: an electronic scientific journal, 11(71), (2014)

14. A. K. Evstafieva, A. B. Krotova, Role and place of the managerial accounting on a basis of the ABC-method in a control system of expenses at the contract building enterprise, Izv. Kazan State Univ. Archit. Civ. Eng., 2 (20), 233-239, (2012)

15. R. M. Ivanova, Investment demand prediction based on economic and mathematical modelling, Izvestiya KGASU,4, 353-364 (2014)

16. L. Gasparenien, R. Remeikiene, A. Skuka, Intellectual Economics, 10, 122-127 (2016)

17. I. Artamonova, B. Khrustalev, Increasing the innovative potential of the enterprise building complex, E3S Web of Conferences, 91, 08033 (2019)

18. H. Alqaralleh, A. Canepa, Economic Modelling, 92, 257-267 (2020)

19. L. Agnello, L. Schuknecht, Journal of Housing Economics, 20, 171190(2010)

20. E. R. de Wit, Englund, M. K. Francke, Regional Science and Urban Economics, 43, 220-241 (2013)

21. O. N. Borovskikh, The main factors that determine the value of a land plot of housing construction, Russ. J. Hous. Res. 5, 367-382 (2018) DOI: 10.18334/zhs.5.3.39437

22. E. Shagiakhmetova, O. Borovskikh, A. Nizamova, T. Kazymova, Multivariate model of construction project operational efficiency, IOP Conf. Ser. Mater. Sci. Eng., 890, (2020) DOI: 10.1088/1757- 899X/890/1/012113 
23. G. Zagidullina, R. Ivanova, R. Sirazetdinov, I. Badykova, E. Biktemirova, Modeling of the innovative activity for the enterprises in investment based construction industry. IOP Conference Series: Materials Science and Engineering, 890(1), 012119 (2020) DOI: 10.1088/1757-899X/890/1/012119

24. I. Artamonova, B. Khrustalev, Increasing the innovative potential of the enterprise building complex, E3S Web of Conferences, 91, 08033 (2019) 